\title{
Blind Magic: Uma tecnologia assistiva para cegos jogarem "Magic: The Gathering"
}

\author{
Cafer Cruz \\ Universidade Federal \\ Fluminense \\ Niterói, Brasil \\ cafer_cruz@id.uff.br
}

\author{
Lucas Tito \\ Universidade Federal \\ Fluminense \\ Niterói, Brasil \\ lucastito@id.uff.br
}

\author{
Gabriel Carrara \\ Universidade Federal \\ Fluminense \\ Niterói, Brasil \\ gcarrara@id.uff.br
}

\author{
Raphael Guerra \\ Universidade Federal \\ Fluminense \\ Niterói, Brasil \\ rguerra@ic.uff.br
}

\author{
Luciana Salgado \\ Universidade Federal \\ Fluminense \\ Niterói, Brasil \\ luciana@ic.uff.br
}

\begin{abstract}
RESUMO
Diversos segmentos da sociedade ainda carecem de integração de pessoas com deficiência visual, como o mercado de entretenimento, onde os jogos são predominantes. Uma das formas de entretenimento favoritas para os jogadores são os jogos de cartas, que não são compatíveis com as necessidades deste público. As adaptações existentes são limitadas, devido ao alto custo, baixa disponibilidade e ao fato de que ainda não é possível aplicá-las em todos os jogos. Entre os jogos de cartas, Magic: The Gathering é o mais jogado do mundo. Este artigo apresenta os resultados de uma pesquisa qualitativa e um processo de co-design com um usuário cego, onde buscamos uma solução para tornar o jogo acessível e inclusivo.
\end{abstract}

\section{ACM Classification Keywords \\ -Social and professional topics $\rightarrow$ People with disabilities; -Software and its engineering $\rightarrow$ Software usability; Soft- ware design engineering;}

\section{Palavras-chave}

Tecnologia Assistiva; Processo de Co-design; Jogo Acessível.

\section{INTRODUÇÃO}

A construção de uma sociedade justa tem como um de seus pilares fundamentais a inclusão ampla, irrestrita e concreta de todas as pessoas, devendo ser indiferente o tipo e grau de deficiência. Entretanto, os mais de 285 milhões de deficientes visuais que existem no mundo [4] apresentam uma qualidade

Permission to make digital or hard copies of all or part of this work for personal or classroom use is granted without fee provided that copies are not made or distributed for profit or commercial advantage and that copies bear this notice and the full citation on the first page. Copyrights for components of this work owned by others than the author(s) must be honored. Abstracting with credit is permitted. To copy otherwise, or republish, to post on servers or to redistribute to lists, requires prior specific permission and/or a fee. Copyright 2018 SBC.

IHC 2018, Anais Estendidos do XVII Simpósio Brasileiro sobre Fatores Humanos em Sistemas Computacionais

Outubro 22-26, 2018, Belém, Brasil

PÔSTERES VIRTUAIS E DEMOS de vida inferior em comparação com aqueles que vivem sem deficiências.

No entanto, a tecnologia mostra-se progressivamente como uma ferramenta útil e poderosa para integrar essas pessoas e, nesse sentido, a tecnologia assistiva se destaca. A tecnologia assistiva (TA) têm como objetivo servir à pessoa com deficiência possibilitando a ela desempenhar funções do cotidiano de forma independente. Entre as categorias poucos exploradas no mundo se destaca a categoria de jogos e entretenimento.

Mesmo a TA sendo pouco usada, é possível encontrar iniciativas para tornar os jogos acessíveis, como é o caso da empresa internacional Maxi-Aids [3]. Além disso, a maioria dos jogos são adaptados em braile. Essa solução limita a variedade de jogos, pois jogos com textos extensos não poderiam ser representados, já que o braile ocupa uma superfície considerável para representação. Como é o caso do jogo Magic: The Gathering, ou simplesmente Magic.

O jogo Magic é um jogo de cartas que possui textos extensos e diferentes em cada carta. Este é o jogo de estratégia de carta possui mais de 20 milhões de jogadores, está disponível em 11 idiomas e com 24 anos de existência no mercado [5]. Além desses fatores é possível encontrar lojas especializadas por todo o país onde os jogadores se reúnem para jogar. Essa peculiaridade poderia aproximar novos jogadores deficientes visuais da comunidade.

Para tornar acessível o jogo Magic foi desenvolvido um aplicativo acessível chamado Blind Magic, que consiste no uso de duas técnicas simples e já existentes. Essas técnicas são o uso do Quick Response (QR) code em cada carta - contendo um código único - e o uso de um smartphone com sistema operacional Android. A construção do Blind Magic contou com a participação de um co-design deficiente visual em todas as etapas de desenvolvimento. O processo de design do aplicativo seguiu os pilares de IHC, fazendo o processo iterativo para a construção da intervenção até o seu desenvolvimento. 


\section{PROCESSO DE DESIGN DO BLIND MAGIC}

$\mathrm{O}$ Blind Magic foi desenvolvido guiado pelo processo de design. A principal característica de um processo de design é o caráter iterativo das atividades até alcançar a proposta final, no qual cada passo da iteração contribui para o refinamento da solução. O Blind Magic contou com 2 (duas) iterações para encontrar uma solução. Todo o processo foi composto por uma equipe de 2 (dois) integrantes, a desenvolvedora e um codesign com deficiência visual. A participação do usuário final permite que seja possível aprender sobre suas necessidades, influenciando positivamente a solução [2].

Resumidamente o processo iterativo se deu da seguinte maneira. Inicialmente foi analisado a situação atual para propor uma intervenção, para isso foram investigados os seguintes aspectos: (i) analise de jogos similares, a fim de conhecer referências com boa avaliação no mercado; (ii) explorar o jogo de cartas Magic, bem como suas regras e o cenário cultural; (iii) definir plataforma de desenvolvimento da intervenção considerando o público alvo. Considerado suficiente a exploração do cenário atual, foi proposto uma intervenção e então construído uma prototipação em papel para ser testado pelo co-design e então desenvolvido. Esse primeiro modelo desenvolvido não foi satisfatório, pois apresentava muitos passos considerados desnecessários, e a leitura do $Q R$ code considerada lenta para a dinâmica do jogo. Com isso, se deu a segunda iteração do processo de design, sendo necessário re-definir o planejamento da intervenção e propor uma nova abordagem. A intervenção considerada suficiente é descrita detalhadamente a seguir.

O processo de design do Blind Magic guiou a solução para a construção de um aplicativo acessível, compatível com o sistema Android 4.4 ou superior. A acessibilidade no aplicativo beneficia os usuários que fazem uso do aplicativo TalkBack. O TalkBack é o leitor de tela nativo nos dispositivos Android [1]. Para realizar os teste com o aplicativo foi adquirido a descrição de um restrito conjunto de cartas para serem usadas na base de dados interna do aplicativo. Foi necessário tomar essa decisão, pois todos os anos são lançadas novas cartas [5]. Para cada carta foi gerado um código único no formato $Q R$ code, quando o aplicativo faz o reconhecimento do $Q R$ code é então feita uma consulta no banco de dados interno e uma resposta é retornada ao usuário.

Com a idealização do design junto a participação do co-design, foram construídas as telas para o aplicativo. A construção dos layouts seguiram os critérios definidos nas diretrizes de acessibilidade do Android $^{1}$. O processo resultou na construção de duas tela, a primeira representa diretamente o leitor das cartas. Quando identificado uma carta é retornado um feedback em formato de vibração e informado a descrição em um formato que pudesse ser consultado de forma iterativa cada campo da carta, as telas podem ser vistas na Figura 1.

\section{CONCLUSÃO}

Este trabalho desenvolveu uma TA para os deficientes visuais jogarem Magic. Para isso, além de contar com a participação do co-design deficiente visual, foi necessário conhecer as

\footnotetext{
1 https: //stuff.mit. edu/afs/sipb/project/android/docs/ design/patterns/accessibility.html
}

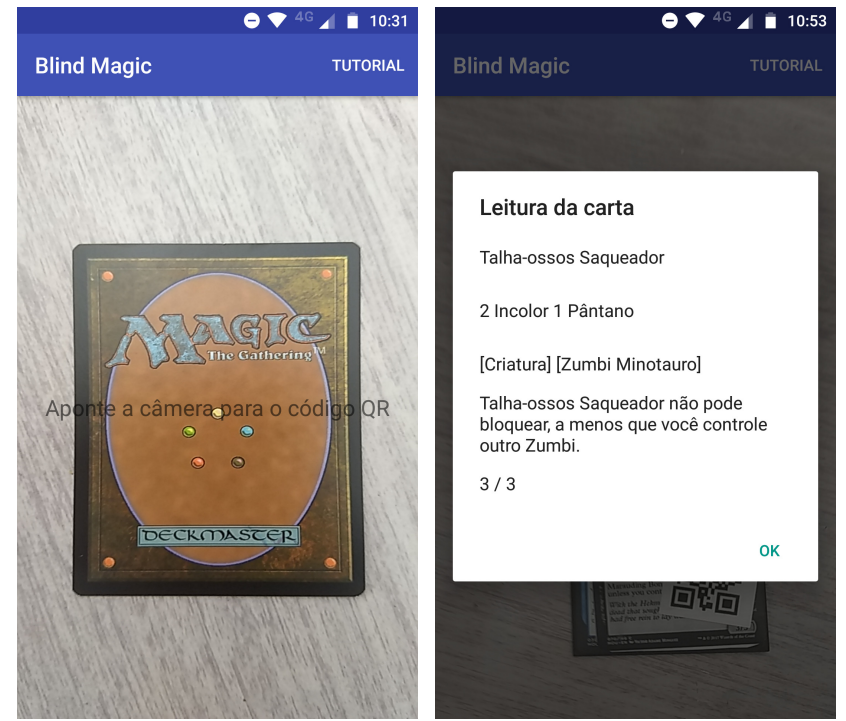

Figure 1. Telas de jogo. A primeira figura contém a tela que permite o identificar o Qr code. A segunda mostra a descrição da carta.

abordagens e as propostas que existiam para jogos de cartas acessíveis, bem como suas limitações. Também foram explorados o funcionamento e as características culturais em que o jogo Magic se aplica.

A partir disso, foi elaborada uma intervenção na qual se baseou a construção do Blind Magic. O desenvolvimento se deu através do processo iterativo com um usuário final deficiente visual no papel de co-design e também contou com as diretrizes de acessibilidade disponíveis na documentação Android. Ao fim do processo de design, foi construída uma TA para deficientes visuais jogarem Magic.

Para utilizá-la o jogador precisa de duas ferramentas: (i) uma lista de $Q R$ codes, que pode ser impressa e (ii) o aplicativo Blind Magic que, necessita de um smartphone com câmera e sistema operacional Android 4.4 ou superior.

\section{REFERÊNCIAS}

1. Android. 2018b. Android Design: Accessibility. (2018b). https://stuff.mit.edu/afs/sipb/project/android/docs/ design/patterns/accessibility.html Accessed: 2018-02-17.

2. S. Barbosa and B. Silva. 2010. Interação Humano-Computador. Elsevier Brasil. https://books. google. com. br/books?id=qkOskwr_cewC

3. Maxi-Aids. 2018. About Maxi-Aids. (2018). https://www .maxiaids.com/t/aboutus Accessed: 2018-03-04.

4. Donatella Pascolini and Silvio Paolo Mariotti. 2012. Global estimates of visual impairment: 2010. British Journal of Ophthalmology 96, 5 (2012), 614-618. DOI : http://dx. doi .org/10.1136/bjophthalmol-2011-300539

5. Wizards of the Coast. 2018a. The history of Magic. (2018a). https://magic.wizards. com/en/content/history Accessed: 2018-05-12. 